\title{
First Come, First Served: Enhancing the Convenience Store Service Experience
}

\author{
Yuan-Ling Chiao1, Ching-Hu Lu ${ }^{2}$, , and Pei-Ling Liu' \\ ${ }^{1}$ Center of Innovation and Synergy for Intelligent Home and Living Technology (INSIGHT Center), National Taiwan University, Taiwan \\ ${ }^{2}$ Yuan Ze University, Taiwan \\ (Received 20 January 2012; Accepted 25 June 2012; Published on line 1 September 2012) \\ *Corresponding author: jhluh@ieee.org \\ DOI: 10.5875/ausmt.v2i3.141
}

\begin{abstract}
One distinctive characteristic of Taiwanese city streets is the omnipresence of convenience stores. These clean, brightly lit stores are in operation 24 hours a day, seven days a week, and offer a wide range of constantly updated lifestyle products and services. Past research in convenience stores have often overlooked the work experiences of convenience store employees, and their contribution to the overall service experience. Thus, the goal of this exploratory study is to explore the convenience store work environment, and to provide some suggestions for in-store technological enhancements. Data was collected through in-depth interviewing, field study observations and Living Lab methodologies. Our research reveals that convenience store employees experience several types of physical, mental and emotional strains throughout their shifts. These strains are often derived from excessive physical exertion and unpleasant interactions with customers. We suggest that certain in-store technological enhancements, such as seamless sensing and seamful actuating, can serve to alleviate employee sense of pressure and anxiety during customer interactions.
\end{abstract}

Keywords: Convenience; frontline service employees; living lab methodologies; seamless sensing; seamful actuating

\section{Introduction}

The convenience store retail format originated in the United States in 1927, and similar stores arrived in Japan in 1964, and then in Taiwan in 1977. Currently, Taiwan has the highest density of convenience stores in the world [1]. According to statistics released by the Fair Trade Commission in Taiwan, there are approximately 9,204 convenience stores in Taiwan, and around 4,209 of these stores are located in Taipei, the capital city. There are four major convenience store chains in Taiwan: Uni-President Enterprises Corporation's 7-Eleven, Taiwan Family Mart Corporation, Hi-Life International Corporation, and OK Mart. 7-Eleven has the largest number of stores throughout the country, followed by Family Mart. The density and quantity of convenience stores means that an average urban citizen has access to a convenience store within approximately every 500 meters in his daily path. At these stores, customers have access to a constantly updated selection of food and beverage items, the ability to make payments for several types of household bills, to arrange for courier services, and to pick up goods ordered from internet shopping sites, and to utilize the sundry of additional services available through the in-store information kiosks.

Previously, literature on convenience stores, particularly in Asian countries, such as those by Terasaka [2] Cheng et al. [3] among others, have been conducted from business, management, marketing and retail perspectives; and provide mostly information regarding consumer demands, logistics systems, marketing strategies, distribution efficiencies, inventory management, electronic ordering systems, and information systems. However, a critical issue regarding the convenience store service experience is missing, and 
that issue is in regards to the effects of customer behaviors on employee work practices. In this research, we are interested in exploring the following questions: What does working in a Taiwanese convenience store entail? What particular strains and obstacles do they face in this type of work environment? How does this type of retail environment, where customers' assumptions of, and expectations for speed and efficiency affect frontline service employees physically, emotionally and mentally? We further explore ways in which technological enhancements can be incorporated into the convenience store environment to improve in-store service experience. In this phase of the study, we pinpoint one aspect of the service experience, which are the instances when customers have to wait in line for a particular service to be executed. Waiting in line is an activity that allows interactions between customers and front line service employees to be directly observed. By observing this

Yuan-Ling Chiao received her Ph.D degree in sociology at the University of Melbourne, Australia. She joined the Center of Innovation and Synergy for Intelligent Home and Living Technology (INSIGHT Center), at National Taiwan University in 2009. She specializes in qualitative research regarding time and space usage in social settings. Her major research interests include analyzing the ways in which the average Taiwanese citizen incorporates convenience store patronage into their daily living patterns. She is also interested in researching the occupational work experiences of convenience store frontline service employees, with particular emphasis on employee job crafting and emotional management skills. Currently, she is also conducting research about the incorporation of learning spaces into residential colleges in Taiwan.

Ching-Hu Lu received Ph.D. degree in computer science and information engineering from National Taiwan University in 2010. Since 2011, he has been a faculty member and assistant professor in the Department of Information Communication at Yuan Ze University, Taiwan. His research interests include human computer interaction, intelligent spaces, machine to machine, context-aware technologies, and topics related to them. Beginning in 2010, Dr. Lu began to participate in a M2M-based context-aware home energy saving project sponsored by National Science Council and the INTEL-NTU Connected Context Computing center. The objective of the project is to minimize the power consumption at home but not to compromise the user comfort using machine learning built upon an M2M infrastructure.

Pei-Ling Liu received her Ph.D. degree in civil engineering from the University of California, Berkeley. She joined the faculty of the Institute of Applied Mechanics, National Taiwan University in the same year. She took directorship of the Institute from 2003 to 2006. She is currently the Director General of the Center of Innovation and Synergy for Intelligent Home and Living Technology (INSIGHT Center), National Taiwan University. Her major research interests include structural reliability analysis and structural health monitoring. She has developed several reliability methods and nondestructive testing methods for concrete structures. In 2006, she won a grant from the National Science Council, Taiwan to conduct the Smart Sustainable Human-Centric Home Project. The objective of the project was to foster interaction between humanities and technology to create a future smart home. The research team was formed by over 30 professors from diverse backgrounds, including mechanical engineering, electrical engineering, civil engineering, medical engineering, computer science, material science, geology, psychology, sociology, social work, medical school, education, history, architecture, and design. In 2008, this project grew into a regional research center of smart living technologies, the INSIGHT Center. Nearly 170 professors from thirty universities are affiliated with this center. Other than conducting multidisciplinary research on smart living technology, the Center runs two living labs: Smart Convenient Store and Smart Elderly Center. INSIGHT Center now focuses on innovation based on user experience. activity, we can also study employee response skills and strategies.

In response to these issues, our research, will also consider how technological enhancements such as wireless sensor network (WSN) technologies can be incorporated into the physical store environment, to support, employees' observational, monitoring and response skills. We will also explore ways to utilize sensors to monitor customers' in-store behaviors. In addition, our multi-disciplinary research team will also consider how "smart" devices, such as mobile phones and interactive screens can serve to alleviate waiting customers' feelings of irritation and boredom, and to potentially encourage more positive and constructive interactions between customers and employees.

\section{Literature Review}

In some respects, the ever-increasing wealth of products and services has certain advantages for customers. However, for a more comprehensive understanding of the convenience store service experience, it is also critical to consider the experiences of the frontline service employees who are providing these services. Other studies, in Western social and cultural contexts, such as those by Mohr and Bitner [4] and Katz [5] have suggested that the experiences of frontline service employees are an important component to consider in the overall process of service experience. In most situations, frontline service employees are the most visible representatives of the company. Their attitudes towards, and interactions with, customers, such as displays of courtesies, friendliness and efficient and effective service delivery have considerable effects on customer satisfaction, as found by Rafaeli [6] Leidner [7] among others.

The nature and content of convenience store work is generally conceptualized as low status, low pay, and monotonous. Convenience store workers are paid minimum wage in Taiwan. Comparatively, they work longer hours, and get paid less than their counterparts working in other retail sectors. Further, their lack of occupational status, or what Hochschild [8] "status shield" leaves them vulnerable to negative customer behaviors, such as the verbal abuse and other types of mistreatment. Customers' disrespect and mistreatment of frontline service employees in other occupations, such as airline staff, and fast food chain employees are similarly documented by Hochschild and Leidner.

One particular source of emotional strain in customer and service provider interactions is in instances where customers have to wait in line for service. Studies 
have shown that among other factors, issues such as line formation and duration of the wait all have effects on the overall service experience Tom and Lucey [9]; Bitner [10] Maister [11] in his study of the psychology of lines found that waiting times feel longer if a person is alone, bored, or anxious. Waiting that is uncertain in duration, or is perceived to be unfair, or unexplained, feel longer than waits that are finite, equitable and explained. Larson (1987) found in his study that an important component of waiting satisfaction is dependent on whether "social justice" is present in the waiting process. Larson asserts, "even if waiting times are very short, customers may be infuriated if the system violates the first in, first out principle. It should be noted that testing sites for queue psychology and waiting behavior have typically been conducted in locations, such as banks, large retail outlets and amusement theme parks, such as Disneyworld (Katz et al. [5] Larson, Maister). These types of public spaces are larger, and not usually a part of the average individual's daily path or routine. During this research process, it became gradually apparent that there is an absence in literature and research regarding waiting in small, confined spaces, that are part of an individual's daily routines, such as convenience stores, where the wait may be unanticipated, spontaneous and unpredictable. Furthermore, previous studies of queue psychology and behavior, such as those by have focused on the feelings derived from waiting from customers' viewpoints, Tom and Lucey [9] Larson [12] Maister [11]. However, more comprehensive and empathetic research on waiting experiences should take into consideration issues on both sides of the service counter, including the feelings and coping mechanisms of the service providers.

Furthermore, we assert that any in-store technological enhancements we propose, should take into considerable consideration the convenience store employees' existing work conditions, work procedures, and workflow. It is our intention to incorporate these technologies in methods that will not further increase employee work burdens and anxiety. Most of prior works [13-15] tries to address how to apply self-service technologies or a middleware, etc. to realize a technology-enhanced convenience store. Due to advances in embedded systems, in this work, we will utilize wireless sensor networks (WSN) and artificial intelligence to preliminarily realize a context-context aware convenience store. This will give us the opportunity to become more attentive to customer in-store behaviors. Furthermore, a smart convenience store can potentially provide assorted services, based on the evidence gathered from all the seamlessly deployed sensors.

\section{Methodology}

In order to thoroughly understand the convenience store work experience, this research was operationalized through the utilization of a triangulation of data collection methods, including ethnographic field studies, in-depth interviews and experience based lab research.

\section{Ethnographic field studies}

In the initial phases of this research, our research team conducted several hours of participant observations within different convenience stores in Taipei and its surrounding suburbs. During these sessions of participant observation, we performed basic in-store actions, such as selecting items for purchase, waiting in line and on occasion, asking for employee assistance. During these sessions, we also paid close attention to the in-store behaviors of other customers, customer-employee interactions, how customers reacted to periods of waiting in line, and employee working conditions, with particular focus on how they dealt with unexpected contingencies. When possible, our research team members took notes, drew rough sketches or took photographs of in-store occurrences, such as line formations, and employees performing their various work tasks.

\section{In-depth interviews}

Subsequently, to further enhance our fieldwork data, we interviewed 16 convenience store employees. We interviewed 11 women and five men, between the ages of 20-25 and 30-35. In alignment with our fieldwork data, interviews were sought from workers from each of the major convenience chain stores, who are employed either full time or part time, and in managerial positions, from both franchise and direct sales stores, working in stores that are in residential areas, commercial districts and in busy thoroughfares, such as train stations, and other urban locations with heavy foot traffic.

The semi-structured interview guideline was devised to focus on two main areas of employee work experiences, (1) On-the job tasks, (2) interactions with customers and (3) employees coping mechanisms and strategies. Most questions were designed to be exploratory and open-ended. Each in-depth interview session typically lasted between 1-2 hours in duration, and were both audio and video recorded, with the interviewees' consent. Afterwards, the interviews were transcribed verbatim and then coded and analyzed, following Glaser and Strauss Grounded Theory Method[16]. 


\section{A Living Laboratory}

In ideal situation, customer behaviors are most realistically studied in their "natural habitat," so to speak. By conducting our research in actual convenience stores, we could observe firsthand, and immediately gauge actual customer responses to our research devices. However, throughout this process, one of the major obstacles we encountered was major convenience store chains' upper managements' reluctance to allow us to obtain access their stores. Their main concerns were that our research might cause potential disruption to their business operations. In addition, there are ethical concerns to consider in regards to obtaining customer data without written consent. Confronted with these managerial constraints and ethical considerations, our research team was unable to conduct certain types of on-site studies, or take photographs or videos of particular parts of our research procedures. To help overcome some of these obstacles, we constructed a replica of a convenience store on the ground floor of our research offices, at National Taiwan University's INSIGHT Center. This convenience store prototype is approximately the size of a typical urban convenience store in Taiwan, and is equipped with the same types of retail equipment, shelving, customer seating, and counter space. In addition, an important advantage is that the lab's infrastructure gave us the opportunity to install various types of still and video cameras and audio recording equipment. The intention behind installing this equipment is to allow us to subsequently observe subtle user reactions, such as body language, gestures and facial expressions, and also how they react and interact within their physical, material and spatial environments.

In contrast to conducting research in a real-life convenience store, in a lab setting, we are able to specify the real life scenarios that we would like to study, such as different types of shifts, (morning rush hour, late night slow periods). We are also able to study more closely how different types of people, such as from different age groups, utilize the convenience store. For example, for other continuing parts of this research, we observed how elderly people navigate the compact retail space, and how they use the in-store informational kiosk.

In addition to studying particular customer behaviors, we were also able to conduct several 'hands on' interview sessions with convenience store employees. During these interactive interviews, they were able to give us concrete accounts of their occupational tasks, and they also were able to walk through our convenience store lab, and point out the various changes they would like to see implemented, to allow them to carry out their work tasks more efficiently. In retrospect, some of our research undertakings, such as the interactive and hands-on interviews sessions, would have been impossible to conduct in a real-life convenience store, given the inherent variety of distractions or interferences.

\section{Findings and Discussion}

In this section, we will first describe the on the job conditions of convenience store workers in Taiwan, and then identify some key problems of their working conditions. Then we will make suggestions for suitable technological enhancements.

\section{Description of work environment}

In terms of physical space, on average, urban convenience stores range between 724 to 987 square feet in size, not including the stockroom, which are usually located towards the back of each store. The stockroom, which is approximately 329 square feet, serves multiple purposes, as a storage space, makeshift office, and locker room.

Employees typically will arrive about 20 minutes prior to the beginning of their shifts. They enter the store and greet colleagues before going into the stockroom to change into their uniform jackets. They punch in their time cards and check the pockets of their uniform jackets to make sure that they have the tools that they may need for the day, such as a ball point pen, marker, highlighter and a razor blade. They might have time to read the company bulletins, but usually they head straight to the cash register, where they change shifts with the cashier.

For a full time convenience store employee, a shift lasts for at least eight hours. Their typical on the job tasks can be broadly divided into three categories: storeroom tasks, behind the counter and over the counter tasks. Storeroom tasks involve office and accounts work and organizing and stocking merchandise. Behind the counter tasks include operating the cash register, processing bill payments, and also include making espresso drinks, microwaving pre-packaged foods and beverages, and locating customers' courier packages, and operating the control buttons for the information kiosk usually located near the front counter of the store. Over the counter tasks consists of maintaining the overall cleanliness and orderliness of the store environment, restocking merchandise and interspersed throughout these tasks are greeting customers and fielding customer queries about a sundry of topics, ranging from street directions, merchandise location and availability, and providing instructions for how to operate the information kiosk. 
Storeroom Tasks

The task of restocking merchandise relies mostly on physical and manual labor. Shelves are restocked periodically throughout the day, as the need arises. Thorough restocking and organization of all merchandise occurs usually during the late night hours, when there are fewer customers in the store. Delivery trucks deliver plastic crates of goods, and the employees must rapidly move and unload the crates onto the display cases. One particular problem we observed during our field studies was that employees will kneel, squat, or stand on tiptoes to place the merchandise into the display cases or shelves. Subsequently, in our in-depth interviews sessions, we enquired if corporate headquarters provided any training about safe lifting, or ergonomics, most of our interviewees laughed at the notion. Most of them explained:

How much I can lift is really based on my personal experience. I just find my own way of doing it. (Female, 20s, part time worker)

Another worker laughed derisively at our inquiry regarding company safety policies regarding restocking merchandise, and said: "[They] don't care how we do it, as long as we do it fast. So we've developed our own ways of lifting things."

We further learned that these methods of lifting are typically learned from accumulated experience, or derived from sheer force of will. Employees have expressed the endurance that it requires to lift heavy objects rapidly and repeatedly, "I just put up with it and try to get it over with as quickly as possible."

Another problem we found was that the compact interiors of urban convenience stores may also cause other types of dangerous occupational practices. Oftentimes, storage spaces are overstocked with merchandise. One female assistant store manager further describes her experience of organizing the boxes of bottled water at the back of the store.

Since there is limited space in the stockroom, we have to stack the [boxes] as high as possible. I'm very short, so I have to stand on a milk carton to hurl the boxes to the top of the stack. There is a specific way to fling the boxes to the top. If you don't do it just right, then all the boxes will topple. If they topple over, you give a shout. We know if there's someone shouting in the back, it's because the boxes of water have fallen over again. (Female, 20s, assistant store manager)

In addition to the potential physical injuries that can arise from organizing large amounts of merchandise in a limited space, from our interviews, we found out that cuts, bruises and burns are the most common types of surface injuries sustained working in a convenience store. One nighttime employee describes,

When I'm stocking merchandise, I often get cuts on my hands from the cardboard boxes or the packing materials. Or because I'm in a rush, I may bump into something. I don't really notice the bumps or cuts until I stop working and then I look down and I realize I have all these cuts and bruises. (Male, 20s, full time employee, night shift)

Other types of chronic injuries our interviewees were prone to are pulled muscles and lower back pain. These injuries are likely to be caused by repeated, incorrect lifting or exertion methods.

\section{Behind the Counter}

Another critical task frontline service employees must carry out is processing customer payments. Major convenience store chains in Taiwan, such as Uni-President 7-Eleven have strict policies that lines are not to exceed over three people in length. Once a fourth person joins the line at the cash register, frontline employees are required to ask their colleagues to abandon other tasks to assist waiting customers. Usually a request for assistance is accomplished by pressing a button located beneath the counter, or by shouting either the names of their colleagues, or simply the phrase "Cash register!" Our field observations revealed that the cashier must shout his/her request a number of times before being heard over the hubbub of the store, or because his/her colleague is occupied with other tasks in the stockroom. Upon arrival at the cash register, usually the cashier will shout, "I can help the next waiting customer." However, it is usually unclear which waiting customer $s /$ he is referring to. Consequently, there is usually a tumult that follows when an additional cash register is opened, as customers vie to be the next served. One store manager, whose store is located near a high school, explains:

We have lines every morning. The line gets so long that it makes a whole circle around the store. If people line up nicely it's better, but sometimes you have people who don't follow the rules. They will crowd the cash register and you wouldn't know who came first. The line is especially frustrating when people don't line up in an orderly way.

Because of the compact size of convenience stores, the lines are usually dense and waiting customers are squeezed in close proximity to each other, and between the merchandise shelves and other browsing customers. 
According to our field observations, we found that the compact store layout made it difficult to form orderly lines over four people. Consequently, customers line up haphazardly, in available spaces, oftentimes in between the merchandise shelves, and it is oftentimes difficult for the employees to visually ascertain whom to serve first.

In the most straightforward situations, a payment transaction takes only a few seconds, and there is minimal interaction, or conversational exchange between customer and employee. One employee explains:

It normally takes 10 to 15 seconds to get rid of a customer, the fastest within 10 seconds, unless the customer wants to get her books or pay her bills, then there will be a line for sure. (Male, 20s, part-time)

However, if the customer chooses to multi-task, and utilize the several different service options, then the checkout procedure is not a simple matter of scanning the item(s)' barcode, taking money and making change. Instead, the transaction may consist of several customizable parts, thus the cashier must perform several steps before the customer can leave the store. $\mathrm{S} /$ he must first listen to, and retain customer requests. Then s/he must mentally design an order of operations prior to turning around to either operate the coffee machine or the microwave, which are located on the counter behind the cash register. Then the cashier will either process the bill payment or begin to search for the online order, which are cash register. Then the cashier will either process the bill payment or begin to search for the online order, which are usually stored in a cabinet underneath the counter. All of these actions must be performed in a highly efficient manner, in the shortest time span possible. However, due to the potentially complex nature of the checkout process, delays are inevitable.

We observed that for the less experienced employees, the acceleration of motions, alongside with their perceptions of customer impatience often leads to stress and confusion, which has a counter effect of slowing them down. One employee explains:

I start to get really nervous. It's like I want my hands to go faster, but they can't. Then I look out at the line and everyone looks really impatient and that makes it even worse... just put my head down and try to go even faster. (Female, 20s, part-time)

Our interviews with employees further revealed that customers' gaze and countenance were a considerable source of pressure for employees working at the front counter. Consequently, one of their coping strategies is to forego pleasantries and accelerate their motions, in order to process customers through the checkout process as quickly as possible. One employee explains:

I just focus on checking out the items because I know all the people are staring at me, so I have to be quick. But what I do is to ignore them so I can focus on the person I am helping, and I find it faster that way. (Male, 20s, full time)

However, despite their best efforts, all of our interviewees mentioned that they were frequently criticized for their efficiency on a daily basis. In a further example, I interviewed an employee that works in a convenience store located in the Taipei Main Station, one of the busiest transportation hubs in Taiwan. She has daily fractious encounters with customers. She says:

Commuters in a rush make really rude comments while they're waiting in line and when it's their turn, they throw the money at me and then just grab their stuff and run out the door. That's really counterproductive, because I have to crawl behind the counter picking up coins and put them into the cash register before I can ring up the next sale. Then it begins again, with the next customer really unhappy with me because I made them wait. (Female, under 20s, part-time)

The majority of the workers that we spoke to for this research mentioned that the constant emotional demands required of them when interacting with customers caused more strain than the physical demands of their jobs.

Over the counter

The employees we interviewed mentioned that they were unable to be in two separate places simultaneously, nor was it possible for them to see every single customer that needed staff assistance every time. For example, one situation where they tended to overlook customers is when customers are operating the self-service machines, such as the information kiosks, or the Slurpee machines. Another assistant store manager further explains:

The [information kiosk] is just like a ticking time bomb. It's a nightmare when it's busy in the store, because we have to spare a person just to help the customer navigate through all the steps on the touch screen panel (Female, 20s, assistant store manager).

The information kiosk allows customers to access an extensive range of transportation, entertainment and online retail and government informational services. 
However, some of the information kiosks in major convenience stores are hampered by an unwieldy interface and dialogue design. In our previous studies, we found that many customers expressed feelings of frustration and annoyance regarding their information kiosk usage experience. They found that they were too many steps required to complete a task, and that the directions provided on the machine were unclear. In these cases, they often seek assistance from the convenience store employees to operate the kiosk for them on their behalf. However, this assistance may also cause some distraction in the employees' workflow. In some stores, the information kiosk is located in locations that are quite a distance from the front counter. Thus, if the convenience store employee is occupied in serving other customers, they may not notice the customer(s) standing in front of the information kiosk who require assistance. Furthermore, if there are several steps required to complete a certain task, the employee must spare several minutes from their task at hand to assist the customer. This in turn causes gridlock in the employee workflow at the cash register, and may increase customers' feelings of impatience and employees' stress levels. This constant alternation from the stockroom, and between the counter and retail floor space also has a negative effect on employees' moods. An assistant store manager describes the content and nature of her work shift:

Our work is scattered. Very scattered. We get distracted a lot. Sometimes we feel really annoyed. (Female, 20s, assistant store manager)

Moreover, despite the fact that many of the products and services are designed by the company to be self-service, some customers will demand that employees wait on them hand and foot. During these instances, employees will usually stop their task at hand, in order to serve the customer. The assistant manager further explains:

A lot of the customers aren't used to doing things for themselves in the store. They expect full service, but a lot of our items are self-service, like the ketchup packets are placed right underneath the hotdog warmer. But they want us to get it for them. Sometimes we try to direct them to the right product by pointing, but they just stand there and expect us to get it for them. (Female, 20s, assistant store manager)

Due to the plethora of services offered by convenience stores in employees must be equipped with a variety of physical, mental and emotional skills and capabilities. These capabilities are not usually learned from corporate employee training. One assistant store manager, who has worked in convenience stores for the past eight years, explains:

Yes. We get training, but you really have no idea how many different things can crop up. There are so many unexpected things that can happen on any given day...You really learn by experience. There are so many different types of customers and they all have different questions and different ways of asking questions. (Female, 20s, assistant store manager)

The convenience store employees we interviewed explained that different types of customers require different types of communication styles and methods, and they must convey information to customers in a specific way, in order to be understood. A storeowner also concurs:

You have to be observant. It is hard to let the customers understand, unless you can be very clear. Sometimes even if you have reminded him, he would still be telling you that he didn't know, and he would file a complaint against you. Even if you do design something that's very clear, there is still the possibility that he would be accusing you of not providing enough information. (Male, 40s, franchise storeowner)

Through our various research methods, we find that convenience store employees face several different types of problems throughout their working hours. (This list is by no means exhaustive; however since it is beyond the scope of this paper to discuss all the issues, they will be explored in subsequent publications)

We find that the physical work environment can be unsafe. We also find that personal health and safety is oftentimes compromised, or even sacrificed for speed and efficiency. Furthermore, employees must quickly and rapidly adjust and adapt their emotional and mental states to cope with the wide variety of customer behaviors they encounter on a regular basis. Our observations and analyses also reveal that in order to alleviate some of the consequences of these problems, convenience store front line employees engage in the critical tasks of noticing, perceiving, absorbing and responding to customers. This task involves a considerable amount of both accumulated experience and consistent effort, but the employee is not given adequate tools to support these skills. In addition to changes that could potentially be made the physical store environment, and to the employee workflow and procedures, we believe that there are some technical enhancements that can be made to the physical store 
environment, which can initiate the process of improving the service environment.

\section{In-store Technological Enhancements}

In order to capture some of customer behaviors in a convenience store setting, we can create a context-aware convenience store. This may help make unavoidable tasks, such as waiting-in-line less daunting for both customers and employees. The proposed implementations are primarily based on the growing attention in ubiquitous computing initiated by Mark Weiser [17] and we hope that the enhanced CVS can better react to customers by providing attentive services.

The first enhancement is the seamless sensing for "quietly" collecting information from both the physical environment of a convenience store and its users (customers and employees) by using wireless sensor network (WSN) and Internet of things (IOTs) related technologies. To accomplish this, we integrated smart sensing technologies into a convenience store. With the deployed technologies, the interactions between a customer and the enhanced convenience store environment will remain the same as usual. Using these seamlessly deployed technologies is particularly important for a smart convenience store due to its variety of customers and their demand in high service availability. We also confirm this ideation with one of the experienced CVS store managers, who is very supportive of this design.

More specifically, in order to detect of the presence of a customer or the number of customers waiting in line, we propose a seamless customer-state detection module that can be deployed in front of a service area (e.g. in front of iBon machine, the ATM, and the cash register). As shown in Figure 1, the prototype of the proposed module consists of several motion-detecting sensors including pressure, Infrared, breakbeam sensors, and an optional laser scanner. These sensors can be easily integrated into a CVS store and be employed to extract features to obtain customers' presence or even more high-level informative contexts (e.g. situation) of customers by analyzing their positions or in-store activities. Although the pressure, Infrared, and breakbeam sensors are useful in detecting the presence of a customer, they become ambiguous in detecting the correct number of customers in some occasions. To address this shortcoming, a laser scanner can be incorporated to assist in tracking the positions of customers' legs and in counting the number of pairs of legs. This way, the system can detect how many customers are in an area of interest (especially in front of the service counter). Since a laser scanner is more expensive, we can selectively deploy the above-mentioned motion-detecting sensors in the areas in front of those single-user self-service machines such as the in-store information kiosks, Slurpee machines, or the automatic teller machines (ATMs) to decrease the overall costs of deployment. Some photos of the sensor deployment are shown in Figure 2. Note that the wireless sensor node for each sensor is not shown in the figure.

Since sensor fusion can improve the accuracy of context recognition, the system can combine the extracted features from the selected motion-detecting sensors and the laser scanner to improve the performance of detecting real-time states of the awaiting customers in a convenience store. Such information can later be utilized to trigger the actuators in the store whenever necessary. For example, the system can trigger voice reminders to call for assistance from another employee working elsewhere in the same store when the system has detected that there are more than five customers waiting in line before the counter. Subsequently, we will further evaluate the effectiveness of this module to see if it needs to be employed for better accuracy improvement.

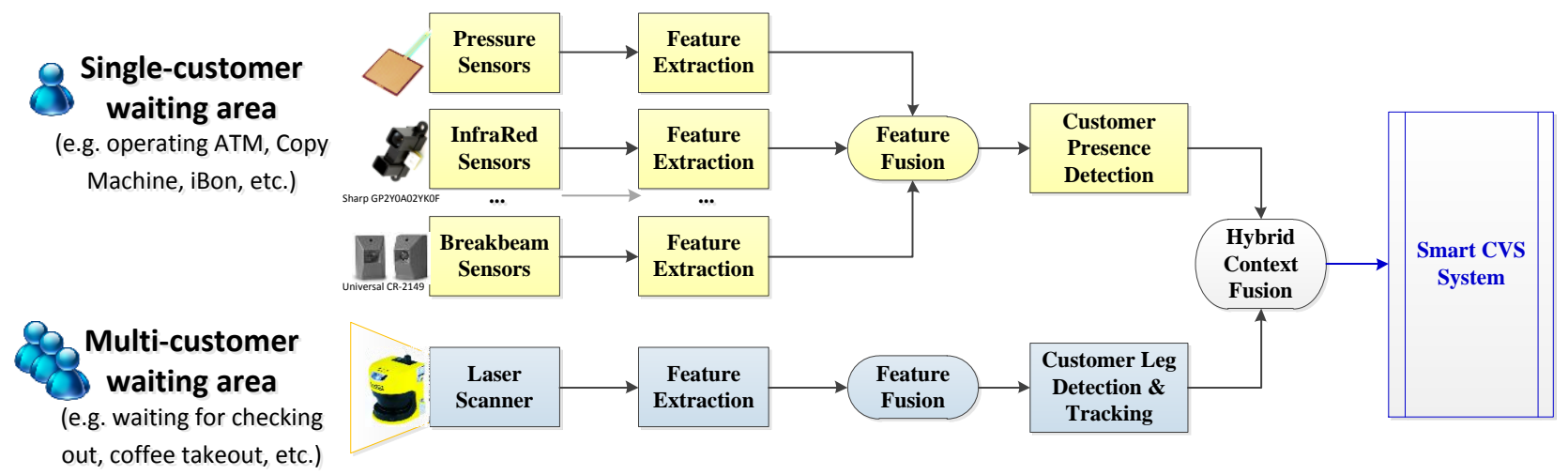

Figure 1. Block diagram of the proposed seamless customer-state detection system. 


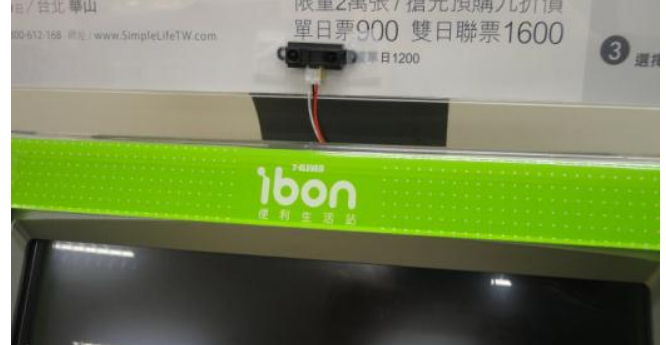

(a) An Infrared sensor on a iBon machine.

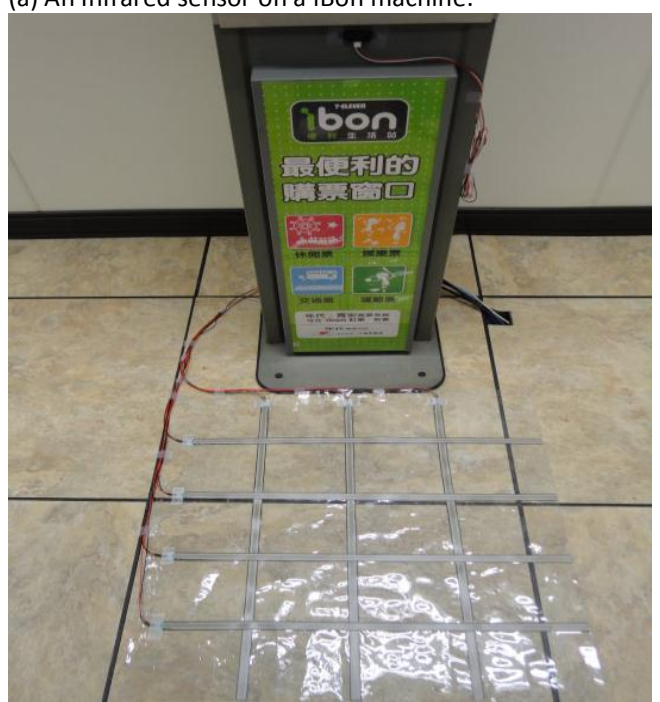

(b) A pressure mat before an iBon kiosk.

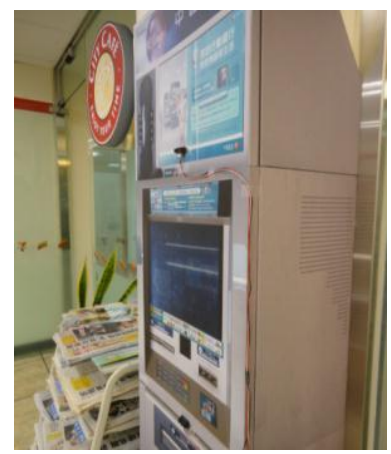

(c) An Infrared sensor on an ATM.

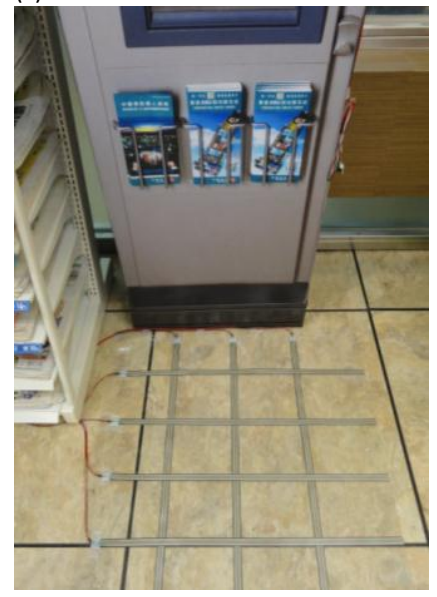

(d) A pressure mat before an ATM.

Figure 2. Sensor deployment for detecting the positions of customers in a convenience store.

The second implementation is the seamful actuating for attentively providing services $[18,19]$ to customers, which is inspired by Chalmers et al. [20] and Broll et al. [21]. Rogers [22] further suggests shifting ubiquitous computing from calming people (i.e. seamlessness) to engaging people (i.e. seamfulness) and therefore enriching user experiences. In the current phase, this concept is preliminarily accomplished by adding a LCD display near the service counter. This screen will display informative and/ or entertaining media contents, and will ideally serve to distract customers from the realization that they are wasting time by waiting in line.

For a preliminary evaluation of this approach, we installed a 17" display screen on the ceiling, behind the service counter (as shown in Figure 3). This screen played commercials with the intention of attracting customers' attention. To test the effectiveness of this approach, we conducted three rounds of field studies and focus groups in the convenience store lab at our research center. Alongside with three real convenience store employees, we invited 16 volunteers to act as customers without knowing in advance that there was a screen to distract their attention. However, from our observations we discovered that the majority of our participants did not pay attention to the screen, during their wait for service
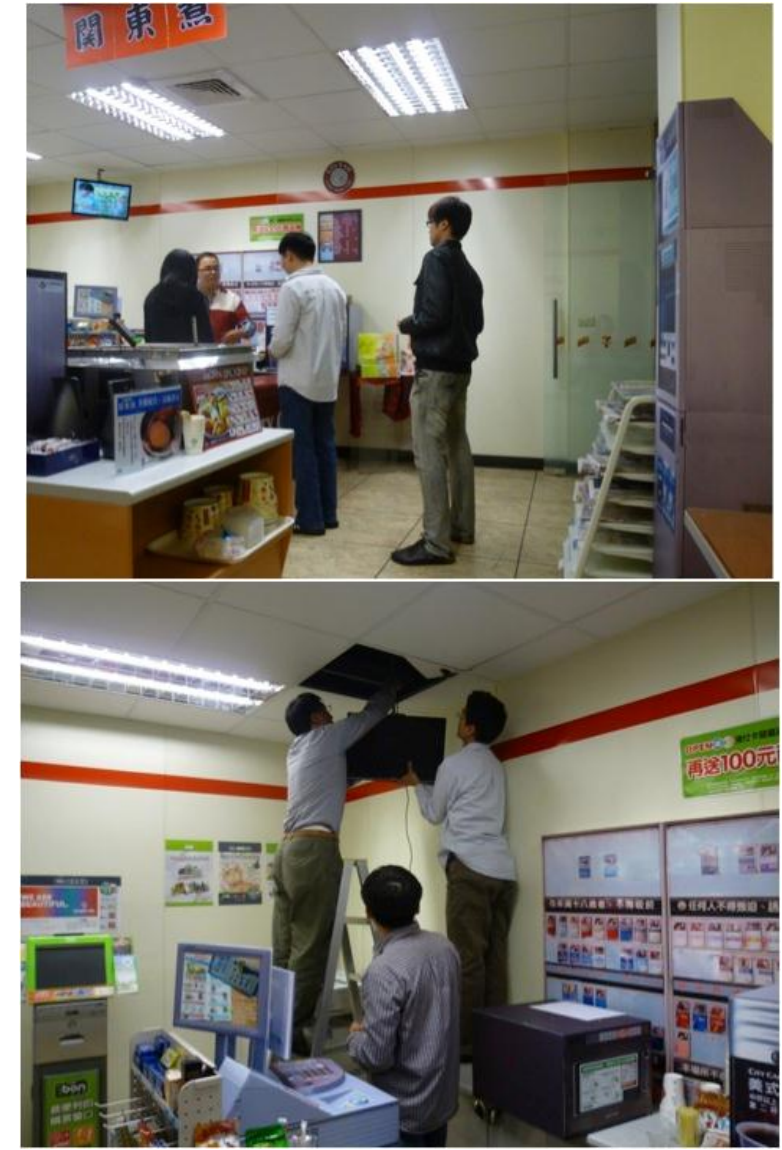

Figure 3. Sensor deployment in the CVS laboratory. 
at the cash register. In our subsequent focus group interviews, our participants mentioned that the screen was not large enough, and was installed at an awkward angle that was too high to attract their line of vision. Moreover, they suggested that if the screen display were accompanied by sound, the screen would have more effectively attracted their attention. Based on their feedbacks, we will pay more attention to the display content, such as color, type of content, and the ways that the content is presented.

In summary, the preceding sections illustrate that there are several contributing factors that make waiting in line physically and mentally uncomfortable for both customers and employees. . Time spent waiting in line may be prolonged because a customer may require more than one service at a time. In this regard, the lack of constructive distractions in the store makes waiting in line uninteresting or even irritating at times. These elements often cause customers to act unpleasantly towards the service providers. Simultaneously, frontline service employees' moods and workflows can be affected negatively by customers' sense of impatience and irritation. Our research suggests that certain improvements must be made to the physical store layout, to encourage more orderly line formations. In addition, our research discovered that employees must also be equipped with more extensive, yet unobtrusive and non-distracting tools, to allow them to increase their observational and monitoring capabilities.

\section{Conclusions and Directions for Further Research}

Convenience stores are an indispensable part of daily life for the average urban citizen in Taiwan. However, oftentimes taken for granted, and/or disregarded are the efforts of the convenience store frontline service employees. At a glance, the nature and content of convenience store work appears to be labor intensive, and monotonous. Workers also appear to be interchangeable and easily replaceable. However, one of our critical research findings reveals that convenience store work is far from mundane. Instead, the workers must possess a wide range of skills to manage frequent spontaneous in-store activities and incidents. At the most basic general and basic level, employees must be equipped with certain interpersonal and emotional management skills in order to provide service to the wide range of customer types that frequent convenience stores. Furthermore, the employees must also be prepared with a wealth of information that is both within and beyond the convenience store product and service parameters. Our interview data reveals that this wealth of information, or knowledge bank, so to speak, is accumulated throughout job tenure and hands-on learning, and work experience. Our interviewees believe that they develop an aptitude for certain tasks, such as explaining, teaching and designing more efficient workflows through their continual interactions with customers and on-the-job experiences. Moreover, they are likely to pass their knowledge and skills down to their trainees. Seasoned employees are a potentially valuable resource to the company, since they can offer customized training and insights that may not be available through the training offered by the company. However, the impetus to develop these employee resources is often mired down by other unpleasant aspects of the job, such as mundane menial tasks and unpleasant customer interactions. In order to cope with the broad scope of on-the-job duties and responsibilities, we discover that employees need to be more sufficiently supported both emotionally and by the in-store technological facilities. Several of the current in-store technologies are developed and implemented with customer benefits in mind. However, we assert that additional technologies need to be developed with consideration of employee requirements and benefits. Our technological enhancements will be developed closely with the intended users' requirements, for their specific environment and circumstances. One of the main implications of our research is that we have initiated the process of deriving the needs for technological enhancements, from direct observations and interactions with the intended users. In the next phases of this research, our research team will invite users, both convenience store employees and customers, to test and give feedback for our enhancements, on an ongoing basis. By maintaining an active learning relationship our users of these technologies, we can ensure that our technological enhancements are help, and not a hindrance to their work experience. Through the utilization of Living Lab methodologies, our multi-disciplinary research team endeavors to develop a more holistic picture of user needs in a convenience store setting. Through the contributions from researchers from the social sciences, technology and design sectors, we strive to develop in-store integrations that are socially, culturally, conscious and user-friendly.

\section{Acknowledgement}

This research was supported National Taiwan University and the National Science Council of Taiwan (NSC 99-2218-E- 002-001). The authors are grateful to the National Taiwan University's INSIGHT Center for their support. We would like to thank Patrick P.L. Rau for his 
comments and suggestions during the earliest stages of this research. We are also grateful for the research assistance of Hui-Wen Yeh and Tsung-Han Yang. Much appreciation is also extended to the convenience store employees who took part in this research.

\section{References}

[1] Convenience store density highest in Taiwan: Report, Taipei Times 2009, [Online].

Available:

http://www.taipeitimes.com/News/biz/archives/2 009/07/10/2003448311 [Accessed: September 9, 2009]

[2] A. Terasaka, "Development of new store types: The role of convenience stores in Japan," GeoJournal, vol. 45, no. 4, pp. 317-325, 1998. doi: 10.1023/a:1006916026245

[3] J. M. S. Cheng, Blankson, Charles, Sutikno, Bayu, Wang, Michael C.H. , "Hybrid convenience stores the changing role of convenience stores in Taiwan," Asia Pacific Journal of Marketing and Logistics, vol. 21, no. 1, pp. 417-423, 2009. doi: $10.1108 / 13555850910973874$

[4] L. A. Mohr, Bitner, Mary Jo, "The role of employee effort in satisfaction with service transactions," Journal of Business Research, vol. 32, no. 3, pp. 239-252, 1995.

doi: 10.1016/0148-2963(94)00049-K

[5] K. L. Katz, B. M. Larson, and R. C. Larson, "Prescription for the waiting-in-line blues: Entertain, enlighten, and engage," Sloan Management Review, vol. 32, no. 2, pp. 44-53, 1991.

Available:

http://search.proquest.com/docview/224965407? accountid=14229

[6] A. Rafaeli, "When cashiers meet customers: An analysis of the role of supermarket cashiers "The Academy Management Journal, vol. 32, no. 2, pp. 245-273, 1989.

Available: http://www.jstor.org/stable/256362

[7] R. Leidner, "Serving hamburgers and selling insurance: Gender, work and identity in interactive service jobs " Gender and Society, vol. 5, no. 2, pp. 154-177, 1991. doi: $10.1177 / 089124391005002002$

[8] A. R. Hochschild, The managed heart : Commercialization of human feeling. Berkeley: University of California Press, 1983.

[9] G. Tom and S. Lucey, "Waiting time delays and customer satisfaction in supermarkets " Journal of Services Marketing, vol. 9, no. 5, pp. 20-29, 1995. doi: $\underline{10.1108 / 08876049510100281}$
[10] M. J. Bitner, "Evaluating service encounters: The effects of physical surroundings and employee responses," Journal of Marketing, vol. 54, no. 2, pp. 69-82, 1990.

Available: http://www.jstor.org/stable/1251871

[11] D. H. Maister, "The psychology of waiting in lines " in The service encounter: Managing employee/customer interaction in service businesses, J. A. Czepiel, M. R. Solomon, and C. F. Surprenant, Eds., Lexington, Mass.: Lexington Books, 1985.

[12] R. C. Larson, "Perspectives on queues: Social justice and the psychology of queuing," Operations Research, vol. 35, no. 6, pp. 895-905, 1987.

Available: http://www.jstor.org/stable/171439

[13] S. Ishii, H. Tsubotani, T. Sano, K. Kobori, M. Koyamada, and A. Uchida, "Applying object technology for the development of convenience store system : Development \& deployment of application framework and middle-ware for convenience store system," IPSJ Magazine, vol. 40, no. 1, pp. 83-88, 1999.

Available: http://ci.nii.ac.jp/naid/110002720778/en/

[14] P. Xiao and C. Sun, "A stock model for convenience store based on technology of automatic replenishment," Logistics Sci-tech, vol. 12, pp. 101-103, 2006.

[15] W. K. Tan and S.-K. Chen, "Using self-service technologies (SST) in a retail setting: A study in Taiwan's convenience store contex," presented at the Conference on Computer Science and Information Systems (MCCSIS 2008) - e-Commerce 2008 Conference, The Netherlands, Amsterdam, 2008.

Available:

http://www.iadis.net/dl/final uploads/200814L02 2.pdf.

[16] B. G. Glaser and A. L. Strauss, The discovery of grounded theory; strategies for qualitative research. Chicago,: Aldine Pub. Co., 1967.

[17] M. Weiser, "The computer for the 21st century," ACM SIGMOBILE Mobile Computing and Communications Review, vol. 3, no. 3, pp. 3-11, 1999.

doi: $10.1145 / 329124.329126$

[18] M. Chalmers and I. MacColl, "Seamful and seamless design in ubiquitous computing," in Workshop At the Crossroads: The Interaction of $\mathrm{HCl}$ and Systems Issues in UbiComp, Seattle, WA, 2003. Available:

http://citeseerx.ist.psu.edu/viewdoc/download?do i=10.1.1.104.9538\&rep=rep1\&type=pdf 
[19] C. H. Lu, Y. C. Lin, and L. C. Fu, "Hide and not easy to seek: A hybrid weaving strategy for context-aware service provision in a smart home," in IEEE Asia-Pacific Services Computing Conference (APSCC), Yilan, Taiwan, 2008, pp. 595-600. doi: 10.1109/APSCC.2008.77

[20] M. Chalmers, I. MacColl, and M. Bell, "Seamful design: Showing the seams in wearable computing," in Eurowearable, 2003. IEE, Birmingham, UK, 2003, pp. 11-16. doi: $10.1049 /$ ic:20030140

[21] G. Broll and S. Benford, "Seamful design for location-based mobile games, entertainment computing - ICEC 2005," in Lecture notes in computer science. vol. 3711, F. Kishino, Y. Kitamura, H. Kato, and N. Nagata, Eds., Berlin; New York: Springer, 2005, pp. 155-166.

doi: $\underline{10.1007 / 1155865116}$
[22] Y. Rogers, "Moving on from weiser's vision of calm computing: Engaging ubicomp experiences ubicomp 2006: Ubiquitous computing," in Lecture notes in computer science. vol. 4206, P. Dourish and A. Friday, Eds., Berlin; New York: Springer, 2006, pp. 404-421.

doi: $10.1007 / 1185356524$ 